\title{
Increased segmental activity and intraluminal pressures in the sigmoid colon of patients with the irritable bowel syndrome
}

\author{
J ROGERS, M M HENRY, AND J J MISIEWICZ \\ From the Department of Gastroenterology and Nutrition, Central Middlesex Hospital, London
}

SUMMARY Intraluminal pressure activity has been recorded in the unprepared true sigmoid colon of seven normal controls (mean age 37 years, range $22-55$, three men) and seven patients with irritable bowel syndrome (IBS) (45 years, 24-75, four men) for 30 minutes before and 100 minutes after a standard $1000 \mathrm{kcal}$ meal. Results differ from previously published data ${ }^{1-31}$ by showing much higher indices of pressure activity with amplitudes up to $490 \mathrm{mmHg}$ in IBS, and $450 \mathrm{mmHg}$ in controls. Study segment activity index and mean pressure wave amplitudes were significantly $(p<0.015$ and $p<0.01)$ higher in IBS than controls, but per cent duration of activity was similar for the whole period of study. During the basal period in controls mean amplitudes recorded from the proximal sigmoid $(40 \mathrm{~cm}$ from anus) were significantly $(p<0 \cdot 01)$ higher than those in the descending colon $(50 \mathrm{~cm})$, distal sigmoid $(30 \mathrm{~cm})$ and rectum $(15 \mathrm{~cm})$. This study shows that the increased colonic activity in IBS is characterised by increased amplitude, but not duration of pressure waves. In the basal state there is a high pressure zone in the proximal sigmoid colon of controls. Pressures in the unprepared colon of controls and IBS were higher than those measured under other experimental conditions.

In most studies of colonic pressure activity ${ }^{1-31}$ a rigid sigmoidoscope was used for insertion of the pressure sensors: this severely limited access to the colon..$^{32}$ In the few studies ${ }^{32-35}$ in which a colonoscope was used, the bowel was prepared and standard colonoscopy premedication was given. These measures were likely to affect subsequent recorded pressure activity.

Studies of colonic pressure activity in patients with the irritable bowel syndrome have thus been largely limited to the rectosigmoid region, and many are probably confined to the rectum. Those studies of colonic pressure activity in which a colonoscope was used are probably not physiological, because the colon was devoid of faeces.

The aim of this study was to measure the pressure response of the unprepared sigmoid colon to a standard meal in controls and patients with the irritable bowel syndrome (IBS).

Address for correspondence: Mr J Rogers, Dept of Gastroenterology and Nutrition, Central Middlesex Hospital, Acton Lane, London NW10 7NS.

Accepted for publication 14 October 1988 .
Methods

\section{PATIENTS}

Seven normal controls (mean age 37 years, range 2255 , three men) and seven patients with the irritable bowel syndrome (IBS) (45 years, 24-75, four men) were studied. Controls were volunteers with no history of gastrointestinal, anorectal or metabolic disorder; all had a regular bowel habit. All patients with IBS had a history of chronic intermittent colicky abdominal pain associated with an irregular bowel habit characterised by variable frequency of bowel action, but without change in stool consistency. All had normal standard laboratory investigations, sigmoidoscopy and a barium enema. In addition, six of the patients had a normal barium meal, small bowel enema and colonoscopy.

Informed consent was obtained from all subjects and the study was approved by the Brent Health Authority Ethical Committee.

All subjects were studied in the morning after 
fasting from midnight. They were not encouraged to attempt defecation before fibreoptic flexible sigmoidoscopy. The fibreoptic flexible sigmoidoscope (Olympus, OSF) was passed to a distance of 60 $\mathrm{cm}$ from the anus in all subjects without preparation of the colon using a minimal amount of air insufflation. Four flexible guide wires (TSF-35-260, W Cook, Europe) were introduced into the colon through the biopsy channel of the sigmoidoscope to $3 \mathrm{~cm}$ beyond its tip. The instrument was then slowly removed over the guide wires, thus maintaining their relative position. During the withdrawal of the sigmoidoscope suction was applied to remove any air introduced into the colon at endoscopy. Four open-ended radioopaque manometric catheters (id $1.3 \mathrm{~mm}$ ) marked in $10 \mathrm{~cm}$ graduations were railroaded over the guide wires, which were then withdrawn. The tips of the catheters were positioned at 50,40,30, and 15 $\mathrm{cm}$ from the anal margin by means of the external distance markings and fluoroscopy. The sites corresponded to the descending, proximal sigmoid, distal sigmoid colon, and the rectum. The catheters were secured to the buttocks by adhesive tape.

Each manometric tube was connected to a pressure transducer (Type P23ID, Statham, Hato Rey, PR) and was perfused with distilled water at a constant rate of $0.25 \mathrm{ml} / \mathrm{min}$ using a pneumohydraulic pump (Mui Scientific, Mississauga, Canada). The electrical signals from the pressure transducers were relayed to a polygraph (Grass 7PD) calibrated at ambient temperature and pressure to $100 \mathrm{mmHg} . \mathrm{cm}$ by mercury manometer. The electrical signal driving each pen-galvanometer was also passed to a matched

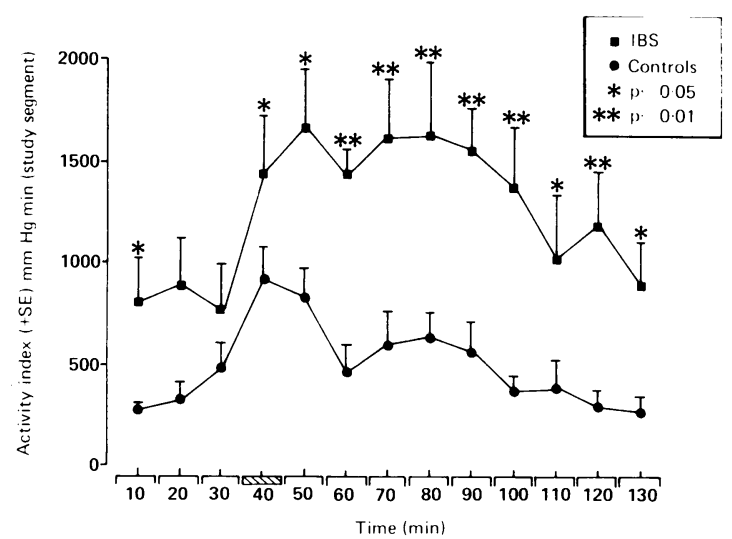

Fig. 1 Study segment activity index in IBS and controls. On the vertical axis the activity index in $\mathrm{mm} \mathrm{Hg}$. $\min$ for 10 minute periods as shown on the horizontal axis. The standard meal is represented by the hatched bar. Activity index was higher in patients than controls. The pattern of activity with respect to time is similar in the two groups. electronic integrator (Grass 7 P10) which enabled synchronous on-line integration of each pressuretime curve, calibrated to $12.5 \mathrm{mmHg} . \mathrm{min} / \mathrm{cm}$.

After positioning the catheters the subjects were placed in a semi-recumbent position and allowed to rest in a quiet laboratory for 30 minutes before recordings were started.

After a 30 minute basal record a standard meal of $1040 \mathrm{kcal}$ (protein: $224 \mathrm{kcal}$, fat: $504 \mathrm{kcal}$, carbohydrate: $312 \mathrm{kcal}$ ) consisting of a cheese sandwich and a milkshake was given and recordings continued for a further 100 minutes.

ANALYSIS OF PRESSURE RECORDS

The records were analysed in 10 and 30 minute epochs for study segment and individual channel pressure activity.

STUDY SEGMENT ANAI.YSIS

Study segment activity was defined as the sum of all the four channels, representing colonic pressure activity from 15 to $50 \mathrm{~cm}$ from the anus. The following variables were derived:-

\section{Activity index}

(Area under curve) was expressed in $\mathrm{mmHg}$. $\mathrm{min}$ and derived by online electronic integration. The analysis of activity index was corrected for base line drift in each individual channel by measurement from the calibrated baseline to actual baseline and a correction factor $(C F)$ derived by formula $C F(n)=d a(n) * d t(n)$ $\mathrm{mmHg} \cdot \mathrm{min}$ where da $=$ unit of pressure drift $\mathrm{Y}$ axis $(\mathrm{mmHg})$ and $\mathrm{dt}=$ time over which drift occurred $\mathrm{X}$ axis $(\min )$, where $(n)=$ epoch number - for example, $1-13$. Activity index epoch length was 10 minutes.

\section{Amplitude spectrum}

This was derived from direct measurements of the pressure tracing and expressed as the number of peaks occurring at intervals of $50 \mathrm{mmHg}$ amplitude: $0-50,51-100,101-150$, etc up to $500 \mathrm{mmHg}$. Amplitude spectrum epoch length was 30 minutes.

INDIVIDUAL CHANNEL ANAIYYSIS

The pressure tracings were analysed by individual channel for the following variables:

Per cent duration of activity

This was measured directly from the pressure tracing and calculated as the fraction of time during which pressure activity occurred, and expressed as a percentage of the epoch. Per cent duration epoch length was 30 minutes.

\section{Mean amplitude}

Mean amplitude was measured directly from the 


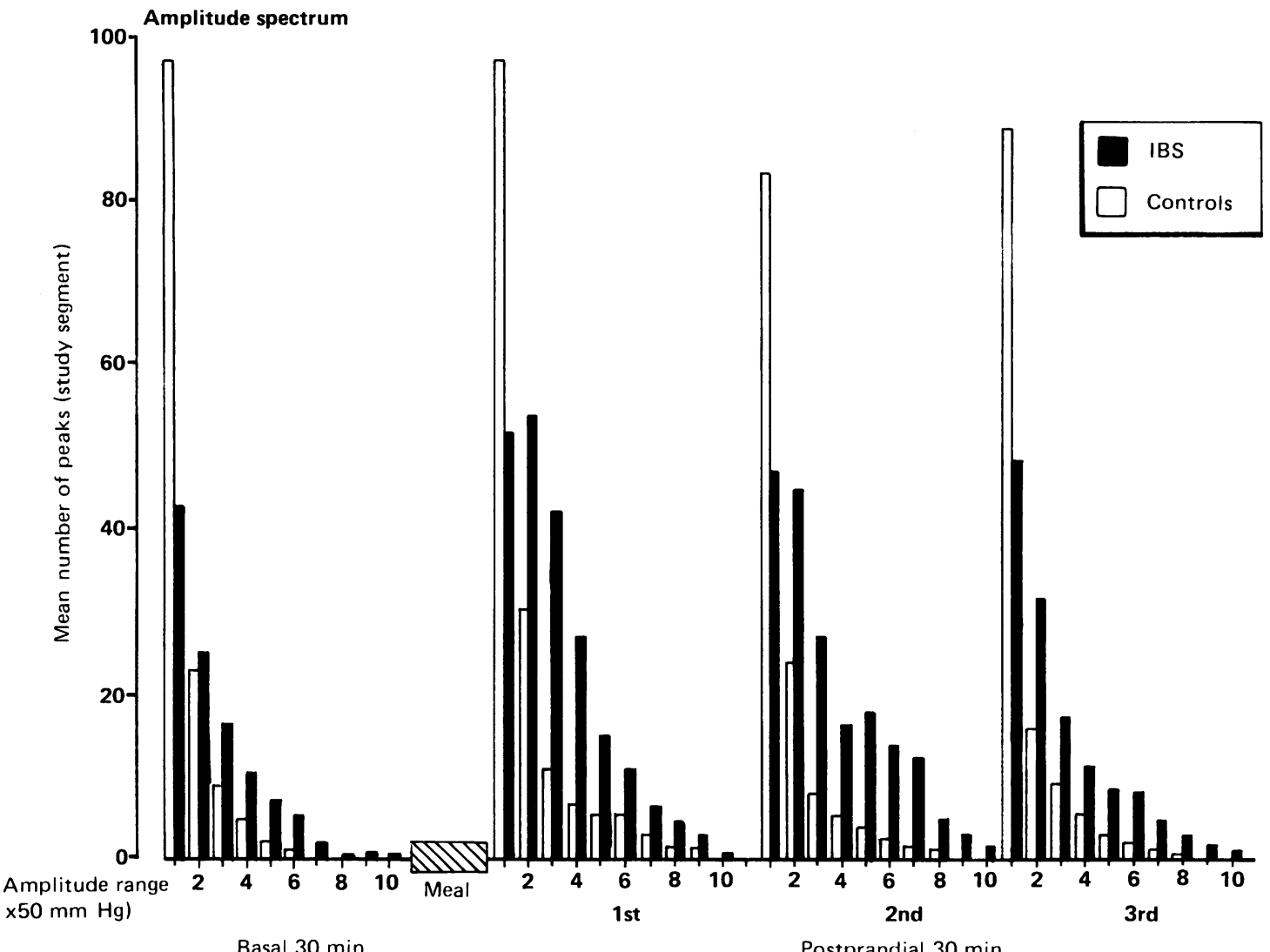

Basal $30 \mathrm{~min}$

Postprandial $30 \mathrm{~min}$

Fig. 2 Study segment amplitude spectrum in IBS and controls for the basal and three postprandial 30 minute periods. The vertical axis shows the mean number of peaks at various amplitude ranges which are represented as 50 mm mercury bands on the horizontal axis. Pressure waves occur in the lower amplitude range in controls, in IBS the spectrum is shifted to the right. The difference is marked in the postprandial period.

pressure trace and calculated as the mean amplitude ( $\mathrm{mmHg}$ ) of peaks occurring in each individual epoch. Mean amplitude epoch length was 10 minutes.

The analysis of amplitude spectrum, mean amplitude and per cent duration of activity depended on accurate definition of a pressure peak. A pressure peak was defined as a point on the pressure trace preceded by a change in pressure of $\geq+10 \mathrm{mmHg}$ and succeeded by a change in pressure of $\geq-10$ $\mathrm{mmHg}$. All data points not meeting this requirement

Table Number of peaks: (mean (SEM))

\begin{tabular}{lll}
\hline & $N C$ & $I B S$ \\
\hline Basal & $135(15)$ & $109(26)$ \\
PCI & $159(13)$ & $212(32)$ \\
PCII & $128(17)$ & $186(29)$ \\
PCIII & $107(23)$ & $134(22)$ \\
\hline
\end{tabular}

were disregarded. Although large amplitude deflections can be produced in water perfused external pressure transducer systems by transient blocking of the manometric tube with faecal material or mucosal folds, the wave form is an easily recognisable artifact which can be excluded from analysis. All such suspect wave forms in this study were excluded.

STATISTICAL ANALYSIS

Manova, $t$ test - separate variance estimate and Mann-Whitney U were used where appropriate.

\section{Results}

All subjects tolerated the study well and only a few complained of any discomfort during intubation. The position of the pressure sensors was checked by fluoroscopy after each study and no change in the relative position of the catheters was detected. The 

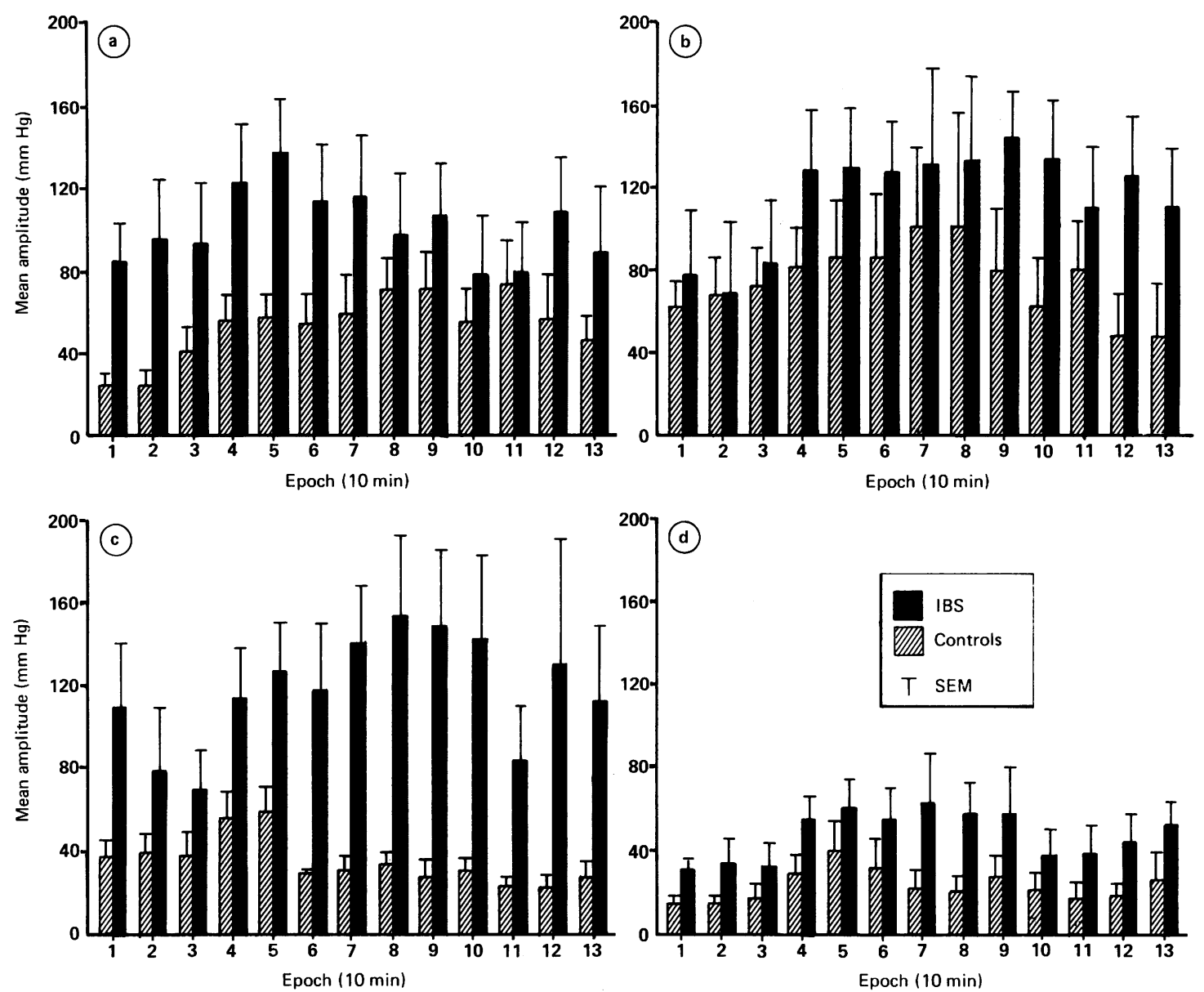

Fig 3 (a) Mean amplitudes (SEM) of IBS and controls at $50 \mathrm{~cm}$; (b) Mean amplitudes (SEM) of IBS and controls at $40 \mathrm{~cm}$; (c) Mean amplitudes (SEM) of IBS and controls at $30 \mathrm{~cm}$; (d) Mean amplitudes (SEM) of IBS and controls at $15 \mathrm{~cm}$.

standard meal was eaten completely by all subjects over a median time of 13.8 minutes $(8-21.2 \mathrm{~min})$ for controls $v 15 \cdot 1$ minutes (8.8-43 min) IBS (NS).

\section{STUDY SEGMENT DATA}

Study segment activity index was significantly ( $<<0.015$, Manova - unique sum of squares) higher in IBS than controls during the whole period of the study (Fig. 1.) In the basal 30 minute period the activity index was higher in IBS than controls, but reached significance only in the first of the three 10 minute epochs. After the meal there was marked and highly significant increase in the activity index in the study segment in patients with IBS which persisted for the remainder of the study. The profile of the change in activity across time was similar $(p=0.337$, Manova, Hotellings) in the two groups.

Analysis of the study segment amplitude spectrum in the basal and the three postprandial 30 minute periods (Fig. 2) shows that in normals most of the pressure waves occur in the lower amplitude ranges while in IBS the spectrum is shifted to the higher ranges. The number of pressure peaks in each period, however, were similar (Table). Mean amplitudes were significantly $(p<0 \cdot 01$, Manova - unique sum of squares) higher in IBS than controls during the whole period of the study.

INDIVIDUAL CHANNEL DATA

Mean amplitudes in individual channels were consistently higher in IBS than controls (Fig. $3 \mathrm{a}-\mathrm{d}$ ). The results of statistical analysis of this variable by channel and epoch are shown as a matrix in Fig. 4. The most consistent separation between the study groups with respect to this variable occurred after the meal in the distal sigmoid $30 \mathrm{~cm}$ from the anus. 


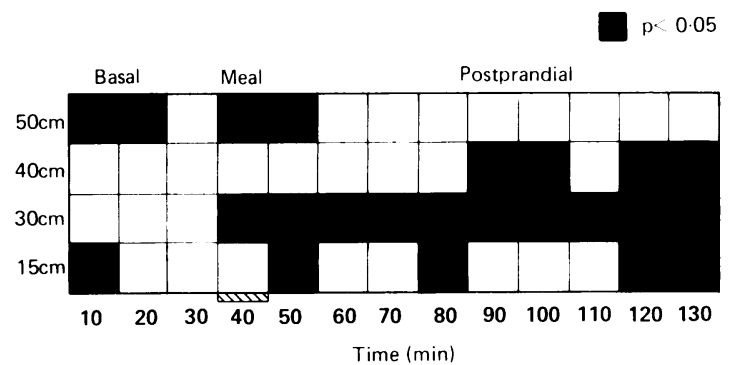

Fig. 4 Matrix by channel and epoch of significant differences in mean amplitude between groups.

Of further interest is the analysis of the mean amplitudes of the individual channels in the basal period (Fig. 5). This shows that in controls the mean amplitudes recorded from the proximal sigmoid (40 $\mathrm{cm}$ from the anus) were significantly $(\mathrm{p}<0.01$, paired $t$ test) higher than those in the descending colon, distal sigmoid, or the rectum.

In contrast, analysis of per cent duration of activity in individual channels (Fig. 6) showed no overall statistical difference before, or after the meal between the two groups.

\section{Discussion}

This study differs from other work because minimal disturbance of normal colonic physiology was secured by avoiding preparation of the colon with laxatives before the study and sedation was not used before insertion of the pressure sensors. The methods by which results are analysed and interpreted have been further developed.

The IBS patients were selected on the criteria of a history of chronic intermittent colicky abdominal pain associated with an irregular bowel habit, characterised by variable frequency of bowel action without change in stool consistency, and normal standard laboratory investigations, sigmoidoscopy and barium enema. Six of the patients had had further investigations which consisted of barium meal, small bowel enema, and colonoscopy all of which were normal. Controls were not sex and age matched, but there was no significant difference between the groups on the basis of these variables.

In comparison with normal controls this study shows increased colonic activity in all pressure variables (apart from per cent duration of activity) in IBS. There was great similarity between the two groups in the profile of activity with time (Fig. 1). The immediate and delayed increase in the study segment activity index occurred synchronously in the two groups studied. The IBS patients had a normal pattern of response to the meal stimulus with respect

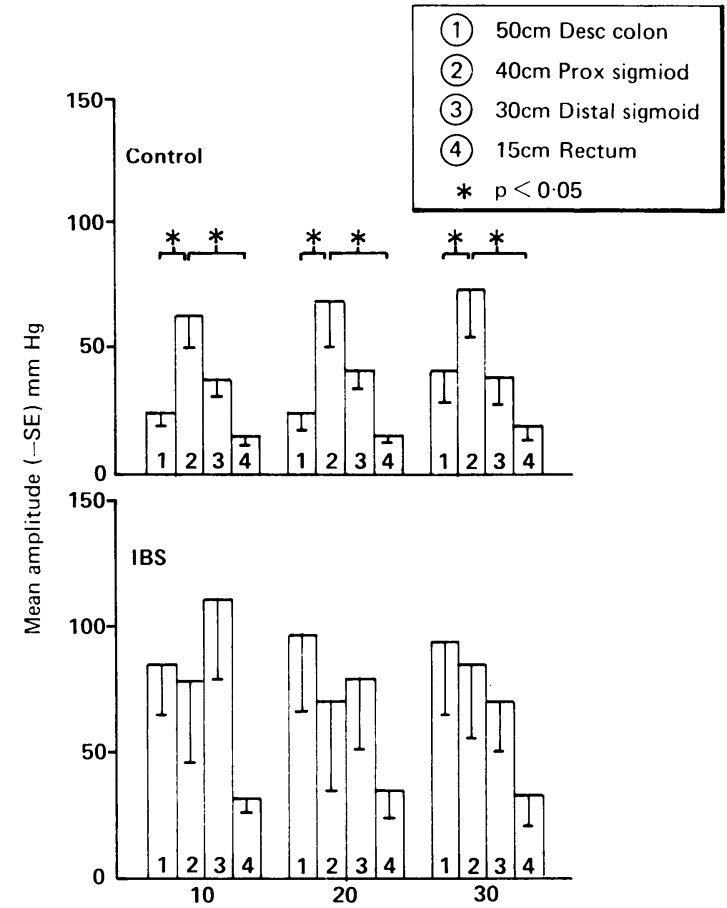

Fig. 5 Mean amplitudes of individual channels in the basal period for controls and IBS. On the vertical axis are the mean amplitudes recorded for each individual channel marked 1 , 2, 3, 4 for descending, proximal sigmoid, distal sigmoid colon and rectum respectively.

to the profile of change over time, but differed in the magnitude of their response with respect to the amplitude of pressure waves. This is at variance with the findings of Sullivan et a $l^{15}$, who found a significant delay in the postprandial increase in colonic motility index in patients with IBS. They also used a $1000 \mathrm{kcal}$ meal stimulus of similar composition, but differed in that pressure activity was recorded at between 5 and $22 \mathrm{~cm}$ from the anal verge.

Analysis of study segment and individual channel data show that the mean amplitudes were markedly higher in IBS than in controls. The mean amplitudes generated by the IBS patients were significantly $(p<0.01)$ higher overall and particularly in the $30 \mathrm{~cm}$ channel throughout the study.

Analysis of the amplitude spectrum shows, that most pressure peaks were of low amplitude in controls and of high amplitude in IBS, although the total numbers of pressure peaks were similar in the preand postcibal periods in the two groups studied (Table).

An interesting observation was the presence of a high pressure zone at $40 \mathrm{~cm}$ from the anus in the 


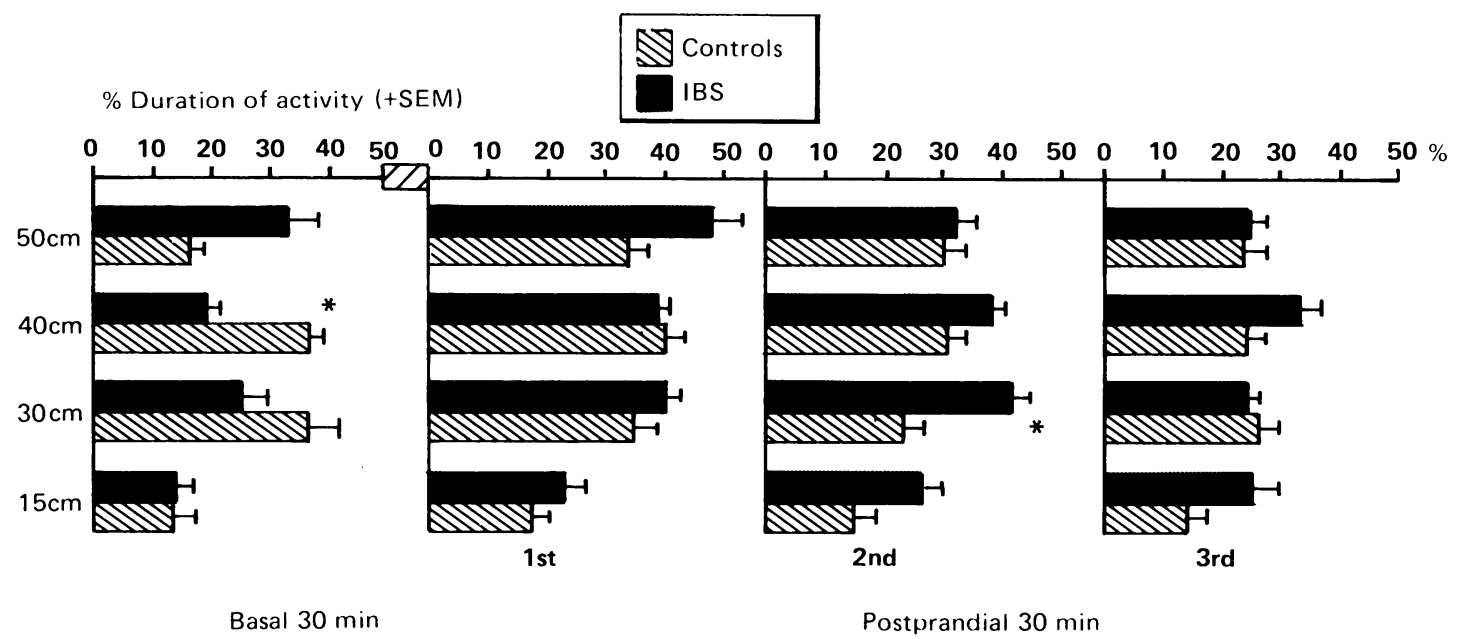

Fig. 6 Mean per cent duration of activity by channel for basal and three postprandial 30 min periods.

sigmoid colon of controls during the basal period. Mean amplitudes in this region were significantly $(\mathrm{p}<0.01)$ higher than in the proximal and distal pressure channels throughout the three basal 10 minute epochs. The proximal sigmoid $(40 \mathrm{~cm}$ from the anus) appears to be a high pressure zone in the normal colon and the distal sigmoid appears to be a transitional zone. In IBS patients the high pressure zone at $40 \mathrm{~cm}$ was extended by the presence of similarly high mean amplitudes in the adjacent proximal and distal channels.

The method of distal colonic intubation in the unprepared bowel using the flexible sigmoidoscope is new. The intubation procedure was straightforward in all subjects. Although no objective measurement of discomfort was made, no difference was noted by the operator between the two groups in the subjective response to the intubation. Only occasionally did a subject complain of mild discomfort on intubation; many of the same subjects have undergone further studies by the same technique.

Pressure records obtained by carefully locating pressure sensors in the unprepared true sigmoid colon differ from previously published data ${ }^{1-31}$ by showing much higher indices of pressure activity in controls and patients with IBS.

In this study pressure waves of amplitudes up to $490 \mathrm{mmHg}$ in IBS, and up to $450 \mathrm{mmHg}$ in controls were recorded. In most previous studies using pressure sensors introduced through rigid sigmoidoscopes mean amplitudes or maximum amplitudes of pressure waves were not reported. ${ }^{1-3}{ }^{1-2} y_{-26} 2 y_{-31}$ Those that did, reported maximum pressures ranging from 17 to $50 \mathrm{~mm} \mathrm{Hg}^{4-4 \times 2728}$ from catheters positioned up to $25 \mathrm{~cm}$ from the anus. In this study the rectal pressure catheter $(15 \mathrm{~cm}$ from the anal verge) recorded mean basal pressures not in excess of $40 \mathrm{~mm} \mathrm{Hg}$ in keeping with these previous studies using rigid sigmoidoscopy.

Previous studies using colonoscopy have reported high amplitude pressure waves ranging from 200 $\mathrm{mmHg}^{33}$ to $220 \mathrm{mmHg}\left(300 \mathrm{~cm} \mathrm{H}_{2} \mathrm{O}\right)^{35}$ in the true, but prepared colon, which was devoid of faeces. This supports our finding that much higher pressures occur in the colon proper, than in the rectum. The evidence thus suggests that previous studies using rigid sigmoidoscopy for the introduction of pressure sensors recorded data from the rectum, rather than from the colon.

The differences between the present and the previous results are most likely caused by the position of the manometric tubes in the true colon and by the presence of faeces in the colonic lumen. Great care was taken to ensure that the intraluminal pressures measured were not artefact because of tube obstruction by faeces, or mucosal contact with the open ended catheters. Bench testing was done to define the characteristics of the artifacts produced by mechanical tube obstruction. These differ markedly in their morphology from true intraluminal pressure waves. Any deflection resembling the tube obstruction artifact was ignored in analysis.

The high intraluminal pressures in the distal colon recorded in this study have several interesting implications in relation to colonic blood flow and the development of colonic diverticula.

Though no direct pressure studies have been made of the mucosal capillary bed of the colon, the mean pressure of the capillary bed of the skin is $27 \mathrm{mmHg}$. ${ }^{36}$ Pressures in excess of this will prevent blood flow. 
Assuming the pressure of the colonic mucosal capillary bed to be similar to the skin, even the intracolonic pressures recorded in previous studies ${ }^{4} \times 272 \times$ would have been sufficient to cause temporary stasis of blood flow. The markedly higher pressures recorded in this study do not necessarily imply any greater disturbance in colonic blood perfusion. As the pressure waves seldom lasted for longer than 30s and were intermittent, mucosal ischaemia is unlikely. The high intraluminal pressures are also interesting with respect to colonic diverticular disease. Increased intraluminal pressure may be the cause of the pulsion diverticula of colonic mucosa which occur in this condition. The additional finding of a high pressure zone in the sigmoid colon of controls may be relevant to the predominance of diverticula in this region.

The analysis and interpretation of the variables of pressure activity, area under curve, mean amplitude and per cent duration of activity are expressed in slightly different ways than used previously. This was done in an attempt to make the analysis of the pressure records more objective.

The activity index, derived by on-line electronic integration allows more accurate calculation of the area under the curve and provides a measurement of the overall amount of 'activity'. The estimate of the correction factor for base line drift is straightforward and accurate.

The amplitude spectrum gives a visual perspective to the data; its measurement is simplified by the strict definition of a 'peak' used in this study. It defines the characteristics of colonic activity by giving a recognisable profile of the number and magnitude of pressure peaks.

Our use of 'study segment' analysis to express the activity index and the amplitude spectrum allows the expression of the overall amount and the nature of pressure activity occurring in the distal colon of each subject.

The use of individual channel analysis for the variables of mean amplitude and per cent duration of activity enable a comparison of the pressure characteristics at each region of the colon studied.

The present techniques have been further developed by incorporating the methods and definitions outlined above into the design of a fully automated computerised system for the analysis of colonic pressure records, which has proved to be fast, accurate and repeatable. ${ }^{37}$

This study shows that the increased colonic activity in IBS is characterised by increased amplitudes, and not by increased duration of pressure activity, and that it is significantly different following a physiological stimulus. Pressures recorded from an unprepared colon are higher than those recorded under other experimental conditions. An important additional finding is that in the basal state there is a high pressure zone in the proximal sigmoid colon of normal controls.

This work was supported by the Medical Research Council.

\section{References}

1 Connell AM, Avery-Jones F, Rowlands EN. Motility of the pelvic colon. Part IV: Abdominal pain associated with colonic hypermotility after meals. Gut 1965 ; 6: 10512.

2 Misiewicz JJ, Holdstock DJ, Waller SL. Motor responses of the human alimentary tract to nearmaximal infusions of pentagastrin. Gut 1967; 8: 463-7.

3 Holdstock DJ, Misiewicz JJ, Waller SL. Observations on the mechanism of abdominal pain. Gut 1969; 10: 1931.

4 Waller SL, Misiewicz JJ, Kiley N. Effect of eating on motility of the pelvic colon in constipation or diarrhoca. Gut 1972; 13: 805-11.

5 Dinoso VP. Meshkinpour H, Lorber SH, Gutierrez JG, Chey WY. Motor responses of the sigmoid colon and rectum to exogenous cholecystokinin and secretin. Gastroenterology 1973; 65: 438-44.

6 Harvey RF, Read AE. Effects of oral magnesium sulphate on colonic motility in patients with the irritable bowel syndrome. Gut 1973; 14: 983-7.

7 Hunt RH. Dilwari JB, Misiewicz JJ. The effect of prostaglandin F2a and E2 on the motility of the sigmoid colon. Gut 1975; 16: 47-9.

8 Weinreich $\mathbf{J}$, Andersen D. Intraluminal pressure in the sigmoid colon: II Patients with sigmoid diverticular disease and related conditions. Scand J Gastroenterol 1976; 11: 581-6.

9 Chowdhury AR, Dinoso VP, Lorber SH. Characterisation of a hyperactive segment at the rectosigmoid junction. Gastroenterology 1976; 71: 584-8.

10 Snape WJ, Jr, Carlson GM, Cohen S. Colonic myoelectrical activity in the irritable bowel syndrome. Gastroenterology 1976; 70: 326-30.

11 Snape WJ. Jr, Carlson GM, Cohen S. Human colonic myoelectrical activity in response to prostigmine and the gastrointestinal hormones. Dig Dis 1977; 22: 881-7.

12 Chowdhury AR, Lorber SH. Effects of glucagon and secretin on food- or morphine-induced motor activity of the distal colon, rectum, and anal sphincter. Dig Dis 1977; 22: 775-80.

13 Snape WJ, Jr, Carlson GM, Matarazzo SA, Cohen S. Evidence that abnormal myoelectrical activity produces colonic motor dysfunction in the irritable bowel syndrome. Gastroenterology 1977; 72: 383-7.

14 Taylor I, Darby C, Hammond P, Basu P. Is there a myoelectrical abnormality in the irritable bowel syndrome? Gut 1978; 19: 391-5.

15 Sullivan MA, Cohen S, Snape WJ, Jr. Colonic myoelectrical activity in irritable bowel syndrome. $N$ Engl J Med 1978; 298: 878-83. 
16 Sullivan MA, Cohen S, Snape WJ, Jr. Colonic myoelectrical activity in irritable bowel syndrome. $N$ Engl $J$ Med 1978; 298: 878-83.

17 Taylor I, Darby C, Hammond P. Comparison of rectosigmoid myoclectrical activity in the irritable colon syndrome during relapses and remissions. Gut 1978; 19: 923-9.

18 Snape WJ, Jr, Matarazzo SA, Cohen S. Effect of eating and gastrointestinal hormones on human colonic myoelectrical and motor activity. Gastroenterology 1978; 75: 373-8.

19 Snape WJ, Jr, Wright SH, Battle WM, Cohen S. The gastrocolonic response: evidence for a neural mechanism. Gastroenterology 1979; 77: 1235-40.

20) Whitehead WE, Engel BT, Schuster MM. Irritable bowel syndrome: physiological and psychological differences between diarrhoea-predominant and constipation-predominant patients. Dig Dis Sci 1980; 25: 404-13.

21 Battle WM, Cohen S, Snape WJ, Jr. Inhibition of postprandial colonic motility after ingestion of amino acid mixture. Dig Dis Sci 1980; 25: 647-52.

22 Wright SH, Snape WJJr, Battle WM, Cohen S, London RL. Effect of dietary components on gastrocolonic response. Am J Physiol 1980; 238: 228-32.

23 Battle WM. Snape WJ, Jr, Wright S, et al. Abnormal colonic motility in progressive systemic sclerosis. Ann Intern Med 1981; 94: 749-52.

24 Abrahamsson H. Dotevall G. Effects of propranolol on colonic pressure in patients with irritable bowel syndrome. Scand J Gastroenterol 1981; 16: 1021-4.

25 Dinoso VP. Murthy SNS, Goldstein J, Rosner B. Basal motor activity of the distal colon: a reappraisal. Gastroenterology 1983; 85: 637-42.

26 Kerlin P, Zinsmeister A, Phillips S. Motor responses to food on the ileum, proximal colon, and distal colon of health humans. Gastroenterology 1983; 84: 762-70.

27 Abrahamsson H. Lyrenas E. Dotevall G. Effects of beta-adrenoceptor blocking drugs on human sigmoid colonic motility. Dig Dis Sci 1983; 28: 590-3.

28 Loeing-Bauche V, Anuras S. Effects of a meal on the motility of the sigmoid colon and rectum in healthy adults. Am J Gastroenterol 1983; 78: 393-7.

29 Narducci F, Bassotti G, Daniotti S, Soldato PD, Pelli MA, Morelli A. Identification of a muscarinic receptor subtype mediating colonic response to eating. Dig Dis Sci 1985; 30: 124-8.

30 Narducci F, Bassotti G, Granata MT, et al. Colonic motility and gastric emptying in patients with the irritable bowel syndrome: effect of pretreatment with octylonium bromide. Dig Dis Sci 1986; 31: 241-6.

31 Greenbaum DS, Mayle JE, Vanegeren LE, et al. Effects of desipramine on irritable bowel syndrome compared with atropine and placebo. Dig Dis Sci 1987; 32: 257-66.

32 Nivatongs S, Fryd DS. How far does the proctosigmoidoscope reach? A prospective study of 1000 patients. N Engl J Med 1980; 303: 380-2.

33 Narducci F, Bassotti G, Gaburri M, Morelli A. Twenty four hour manometric recording of colonic motor activity in healthy man. Gut 1987; 28: 17-25.

34 Sasaki D, Kido A, Yoshida Y. An endoscopic method to study the relationship between bowel habit and motility in the ascending and sigmoid colon. Gastrointest Endosc 1986; 32: 185-9.

35 Trotman IF, Misicwicz JJ. Sigmoid motility in diverticular disease and the irritable bowel syndrome. Gut 1988; 29: 218-22.

36 Ganong WF. Review of medical physiology. California: Lange, 1973.

37 Rogers J, Misiewicz JJ. Fully automated computer analysis of intracolonic pressures. Gut 1988; 29: 642-9. 